Tohoku J. exp. Med., 1978, 125, 53-57

\title{
Diagnosis of Persistent Truncus Arteriosus by Two-Dimensional Echocardiography: A Case Study
}

\author{
Yoshiro Yoshida, Morikuni Fukuda, Motonao Tanaka* \\ and Yoshio Terasawa* \\ Department of Pediatrics, Tohoku University School of Medicine, \\ and ${ }^{*}$ Division of Cardiology and Medical Electronics of the \\ Research Institute for Tuberculosis, Leprosy and Cancer, Tohoku \\ University, Sendai 980
}

\begin{abstract}
Yoshida, Y., Fukuda, M., Tanaka, M. and Terasawa, Y. Diagnosis of Persistent Truncus Arteriosus by Two-Dimensional Echocardiography: A Case Study. Tohoku J. exp. Med., 1978, 125 (1), 53-57 — Two-dimensional echocardiography of a patient revealed overriding of the large aortic trunk which bifurcated above the semilunar valve, suggesting persistent truncus arterious. This diagnosis was confirmed by cardiac catheterization and angiocardiography. Surgery and autopsy also confirmed the accuracy of the two dimensional echocardiographic findings. Two-dimensional echocardiography is thus valuable in diagnosing persistent truncus arteriosus. — two-dimensional echocardiography; persistent truncus arteriosus
\end{abstract}

Persistent truncus arteriosus is an uncommon form of congenital heart disease with a wide spectrum of anatomy and clinical severity. Clinical diagnosis is sometimes very difficult requiring cardiac catheterization and angiocardiography. The purpose of this paper is to present the two-dimensional echocardiographic findings of a case of persistent truncus arteriosus and to re-stress the usefulness of this non-invasive method for the diagnosis of this malformation.

\section{Case Report}

A 7-month-old boy with failure to thrive was admitted to the Tohoku University Hospital for further examination of the heart. At birth he had meningocele cystica which was excised at the age of 1 month. Since his birth, he had been always tachypneic and showed retraction of the chest wall on inspiration. His weight gain was very poor. A cardiac murmur was noticed from 4 days of life. At the age of 2 months he was admitted for pneumonia. At that time a diagnosis of large ventricular defect was made and he was given digitalis derivative and antibiotics. Wheezing and retraction of the chest wall and excessive perspiration were present. No cyanosis appeared. At the age of 7 months he was readmitted for further evaluation of the congenital heart disease.

Received for publication, September 24, 1977. 

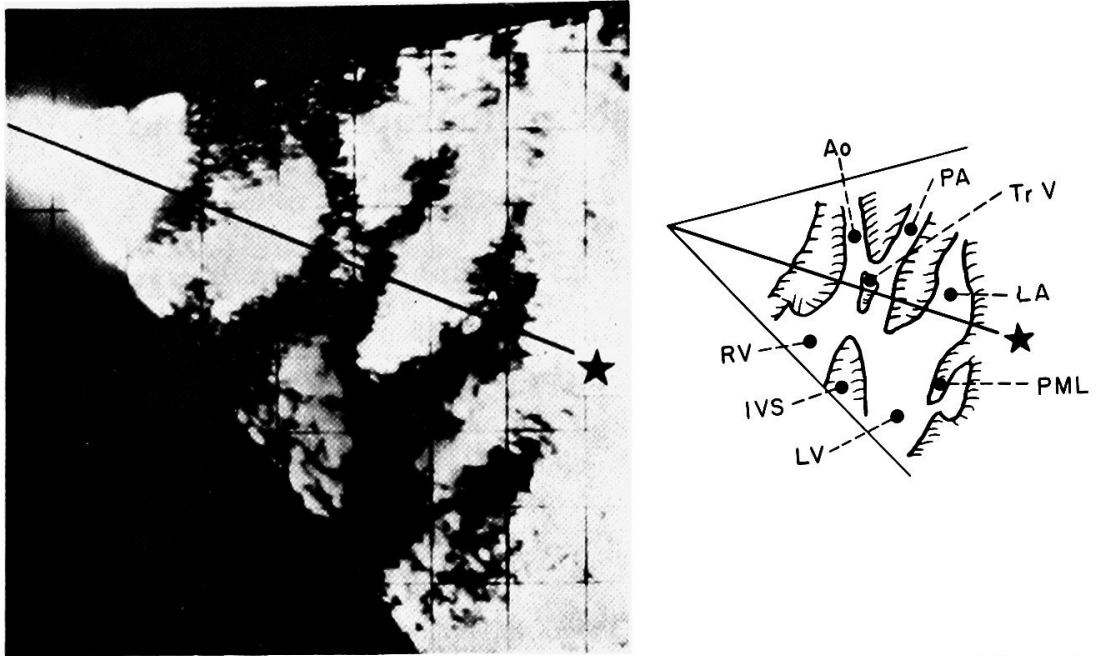

Fig. 1. Two-dimensional echocardiogram along the long axis of the heart. The asterisk indicates the position of the semilunar valve (truncal valve).

Ao, aorta; IVS, interventricular septum; LA, left atrium; LV, left ventricle; PA, pulmonary artery; PML, posterior mitral leaflet; $R V$, right ventricle; $\mathrm{TrV}$, truncal valve.

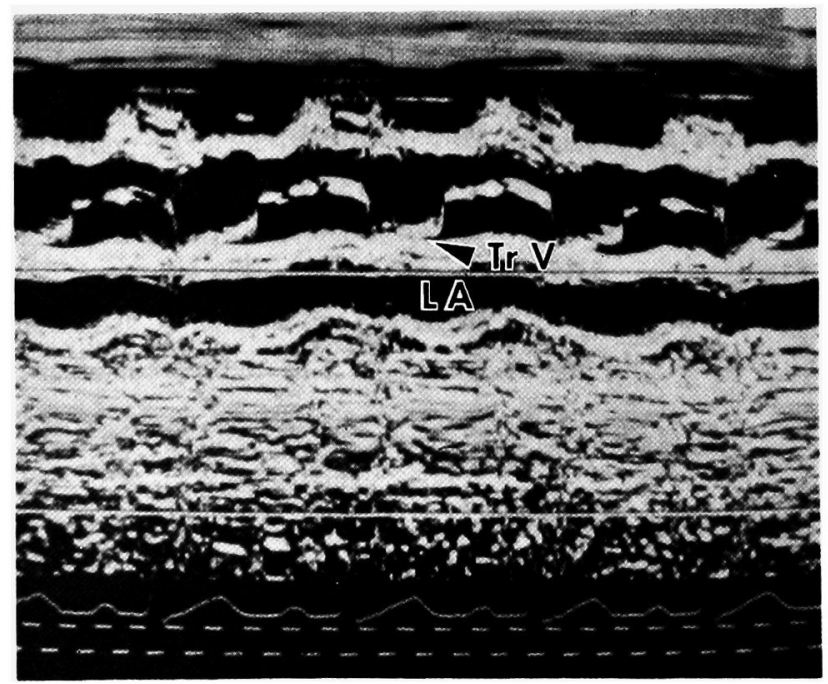

Fig. 2. An echocardiogram of the semilunar valve of which position is indicated in Fig. 1 .

The abbreviations are the same as in Fig. 1.

Physical examination revealed an emaciated, tachypneic, and slightly pale boy weighing $5,820 \mathrm{~g}$ without cyanosis. Dry rales were audible on all over the chest. A systolic murmur of grade $3 / 6$ was audible at the lower left sternal border, an early systolic click was present and the second sound was slightly accentuated. The liver was palpable $5 \mathrm{~cm}$ below the right costal margin. No clubbing of fingers 
or toes was noticed. The chest $\mathrm{x}$-ray photo showed moderate cardiomegaly (cardio-thoracic ratio: 0.59) and increased pulmonary vascularity. The electrocardiogram was interpreted as follows: right axis deviation (the mean electric axis: $+110^{\circ}$ ), right ventricular hypertrophy, incomplete right bundle branch block.

\section{Echocardiography}

Two-dimensional echocardiography was performed after the method of Tanaka et al. (1971). The probe was set at the second intercostal space along the left sternal border and ultrasonic sector scanning was performed manually. The two-dimensional patterns were obtained at various cardiac phases of the cardiac cycle using the $R$ wave of the electrocardiogram as the trigger signal. M-mode echoes were obtained in several directions within the plane of imaging, including the level of the semilunar valve. Fig. 1 shows the end-diastolic pattern. A large sized great vessel overriding the ventricular septum was observed to bifurcate $1.5 \mathrm{~cm}$ above its origin. No other great vessel could be found at any other level or plane. The echocardiogram of only the semilunar valve was shown in Fig. 2. The caliber of the vessel was very large measuring about $2.4 \mathrm{~cm}$. The ultrasonic examination suggested the diagnosis of persistent truncus arteriosus.

\section{Cardiac catheterization and angiocardiography}

The catheterization data showed a remarkably increased ratio of pulmonary to systemic blood flow (Qp/Qs: 4.0). The right and left ventriculograms showed simultaneous opacification of the aorta and the pulmonary artery. The lateral view of the aortogram (Fig. 3) clearly showed the pulmonary artery arising from the posterior side of the aorta above the semilunar valve, and this confirmed the diagnosis of persistent truncus arteriosus type I.

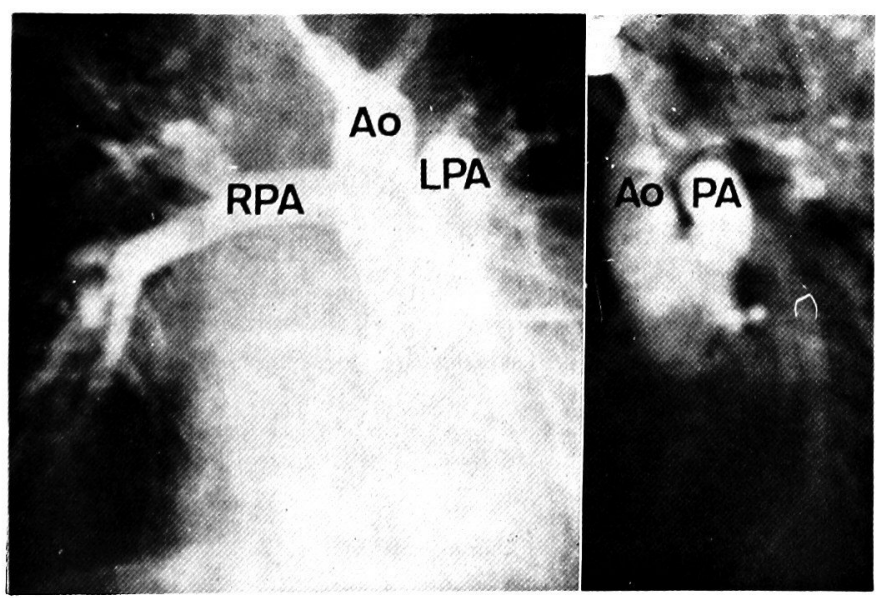

Fig. 3. Aortograms. Posteroanterior and lateral views. See text. Ao, aorta; LPA, left pulmonary artery; RPA, right pulmonary artery. 


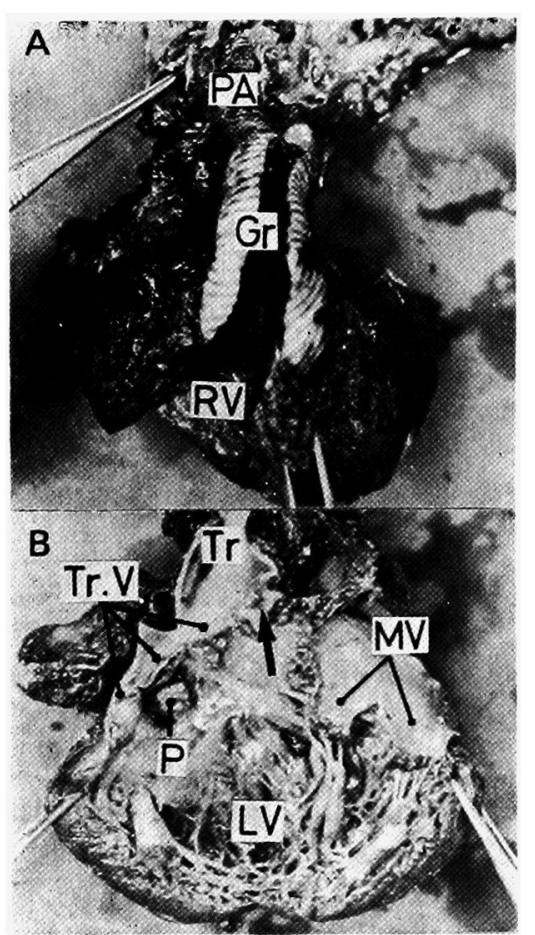

Fig. 4. A: Anterior view of the autopsy specimen. B: Opened view of the left ventricle. See text. Gr, tube graft; MV, mitral valve; $\mathrm{P}$, the patch closing the ventricular septal defect; Tr, truncus arteriosus. The other abbreviations are the same as in Fig. 1.

\section{Surgery and postoperative course}

The diagnosis of persistent truncus arteriosus type I was confirmed at surgery and total correction constructing the outflow tract from the right ventricle to the main trunk of the pulmonary artery and closing the ventricular septal defect was performed, but the patient died in the same night of the operation.

\section{Autopsy}

Fig. $4 \mathrm{~A}$ is the anterior view of the heart. An autologus pericardial valve bearing tube graft is by-passed from the right ventricle to the main trunk of the pulmonary artery. Fig. 4B is the opened view of the left ventricle. The truncal valve has three cusps. The ventricular septal defect is closed with a patch. The arrow points to the site of origin of the pulmonary artery which was separated at surgery. The pathological diagnosis is persistent truncus arteriosus type I which was totally corrected.

\section{Discussion}

Recently several reports on echocardiographic findings of persistent truncus arteriosus have been published (Chung et al. 1973; Chandraratna et al. 1974; 
Sahn et al. 1974; Godman et al. 1974; French and Popp 1975; Murphy et al. 1975). The findings reported are: (1) large aortic root overriding the ventricular septum, (2) failure to detect the pulmonic valve, (3) multiple and unusual cusp echoes, (4) fine diastolic fluttering of the anterior mitral leaflet, (5) four-leaf truncal valve in one case, and (6) paradoxical movement of the ventricular septum. The most important of these is the first one, overriding of the large aortic root above the ventricular septum. This finding is also present in other congenital heart diseases. Cases which show overriding of the aorta are separated into two groups. Group 1: Cases which show decreased pulmonary vascularity on chest $\mathrm{x}$-ray photos, i.e. tetralogy of Fallot, pulmonary atresia with ventricular septal defect and persistent truncus arteriosus type IV (Collett and Edwards 1949). Group 2: Cases which show increased pulmonary vascularity on chest $\mathrm{x}$-ray photos, i.e. persistent truncus arteriosus types I, II, III (Collett and Edwards 1949). Persistent truncus arteriosus type IV is indistinguishable from pulmonary atresia with ventricular septal defect by noninvasive methods including echocardiography.

In our case the two-dimensional echocardiography directly demonstrated the overriding large aortic root which bifurcated above the semilunar valve and this led to the diagnosis of persistent truncus arteriosus type I. Furthermore, surgery and autopsy confirmed the two-dimensional view correctly represented anatomical relationships among the aorta, pulmonary artery and the ventricular septum.

This case report reveals that two-dimensional echocardiography is useful in diagnosing the persistent truncus arteriosus.

\section{References}

1) Chandraratna, P.A.N., Bhaduri, U., Littman, B.B. \& Hildner, F.J. (1974) Echocardiographic findings in persistent truncus arteriosus in a young adult. Brit. Heart $J ., 36,732-736$.

2) Chung, K.J., Alexon, C.G., Manning, J.A.\& Gramiak, R. (1973) Echocardiography in truncus arteriosus. Circulation, 48, 281-286.

3) Collett, R.W. \& Edwards, J.E. (1949) Persistent truncus arteriosus: A classification according to anatomic types. Surg. Clin. North Amer., 29, 1245-1265.

4) French, J.W. \& Popp, R. (1975) Variability of echocardiographic discontinuity in double outlet right ventricle and truncus arteriosus. Circulation, 51, 848-854.

5) Godman, M.J., Tham, P. \& Kid, B.S.L. (1974) Echocardigoraphy in the evaluation of the cyanotic newborn infant. Brit. Heart $J ., 36,154-166$.

6) Murphy, K.F., Kotler, M.N., Reichek, N. \& Perloff, J.K. (1975) Ultrasound in the diagnosis of congenital heart disease. Amer. Heart J., 89, 638-656.

7) Shan, D.J., Terry, R., O'Rourke, R., Leopold, G. \& Friedman, W.F. (1974) Multiple crystal cross-sectional echocardiography in the diagnosis of cyanotic congenital heart disease. Circulation, 50, 230-238.

8) Tanaka, M., Neyazaki, T., Kosaka, S., Sugi, H., Oka, S., Ebina, T., Terasawa, Y., Unno, K. \& Nitta, K. (1971) Ultrasonic evaluation of anatomical abnormalities of heart in congenital and acquired heart diseases. Brit. Heart $J ., 33,686-698$. 